\title{
An improvement of the Ts-NDVI space drought monitoring method and its applications in the Mongolian plateau with MODIS, 2000-2012
}

\author{
Xiaoming $\mathrm{Cao}^{1} \cdot$ Yiming Feng ${ }^{1} \cdot$ Juanle Wang ${ }^{2,3}$
}

Received: 29 April 2015 / Accepted: 30 March 2016/Published online: 14 May 2016

(C) Saudi Society for Geosciences 2016

\begin{abstract}
Surface soil moisture is a key variable to describe water and energy exchanges at the surface/atm interface and measure drought and aridification. The Ts-NDVI space is an effective method to monitor regional surface soil moisture status. Due to the disturbance of multiple factors, the established dry or wet boundary with monotemporal remote sensing data is unstable. This paper developed a Ts-NDVI triangle space with MODIS NDVI dataset to monitor soil moisture in the Mongolian Plateau in 2000-2012. Based on the temperature vegetation dryness index (TVDI), the spatiotemporal variations of drought were studied. The results indicated that (1) the general Ts-NDVI space method is an effective way to monitor regional soil moisture. However, if the single time space shows perfect structure, there would be no differences between the inverted results of the single time space and the general space. (2) The TVDI calculated in the paper is expected to show the water deficit for the region from low (bare soil) to high (full vegetation cover) NDVI values, and it is found to be in close negative agreement with
\end{abstract}

Juanle Wang

wangjl@igsnrr.ac.cn

Xiaoming Cao

caoxm@caf.ac.cn

Yiming Feng

fengym@caf.ac.cn

1 Institute of Desertification Studies, Chinese Academy of Forestry, Beijing 100091, China

2 State Key Laboratory of Resources and Environmental Information Systems, Institute of Geographical Sciences and Natural Resources Research, Chinese Academy of Sciences, Beijing 100101, China

3 Jiangsu Center for Collaborative Innovation in Geographical Information Resource Development and Application, Nanjing 210023, China precipitation and soil moisture; changes in the TVDI are dependent on the water status in the study area. (3) In the Mongolian Plateau, TVDI presented a zonal distribution with changes in Land Use/Land Cover types, vegetation cover, and latitude. Drought was serious in bare land, construction land, and grassland. Drought was widely spread throughout the Mongolian Plateau, and there was aridification in the study period. Vegetation degradation, overgrazing, and climate warming could be considered as the main reasons.

Keywords The general Ts-NDVI space $\cdot$ Aridification $\cdot$ The Mongolian Plateau $\cdot$ Remote sensing

\section{Introduction}

Due to climate warming, the continuous increase of temperature has resulted frequent droughts (Li et al. 2004; Shu et al. 2011). The central Asia and Northwest China have been considered one of these regions where the drought events occurred frequently, especially in the past 20 years (Jacoby et al. 1996; Zhao et al. 2006; Wang et al. 2008a, b; Seneviratne et al. 2002). From 1947 to 2006, more than $80 \%$ of the land area in the Eastern hemisphere suffered aridification, which was more obvious in Northern Africa and along the China-Mongolia border (Shi and Liu 2012). The observations in Mongolia also indicate that aridification had become more serious over the last 40 years (Shi et al. 2002).

Drought is an important disaster, and would lead to more regional disasters, such as degradation, soil and water loss (Gao et al. 2011). Soil moisture (SM) is a critical factor in various environmental studies and is used as a key variable in several applications such as drought severity and duration, soil erosion, etc. (Wang et al. 2004; Xu 2006; Parinaz et al. 
2012; Rahimzadeh et al. 2013). Soil moisture could be used to monitor the region drought with water characteristics of strong absorption in shortwave infrared band (Gao et al. 2011). Since the 1980 s, a number of remote sensing indices (vegetation index, VI), such as, the normalized difference vegetation index (NDVI), the vegetation condition index (VCI) (Kogan 1995), the normalized difference water index (NDWI) (Mcffters 1996), etc., have been developed to investigation vegetation condition and amount or soil moisture for drought monitoring (Tucker et al. 1981; Malo and Nicholson 1990; Anyamba and Tucker 2005; Vicente-Serrano et al. 2006; Sun et al. 2013; Chandrasekar and Sai 2015). However, one single vegetation index could not reflect the surface condition comprehensive. For example, NDVI is often referred to as a greenness index which represents the vegetation amount and chlorophyll content of vegetation rather than the water status of the region. Therefore, there is a need for a more sensitive indicator to reflect water stress monitoring (Rahimzadeh et al. 2013). The land surface temperature (Ts) is an efficient indicator of energy distribution at the surface. Based on the negative correlation between the Ts and NDVI (Goetz 1997), the vegetation index/temperature trapezoid eigenspace (VITT) was proposed (Sandholt et al. 2002). Based on VITT, Sandholt et al. (2002) proposed the temperature vegetation dryness index (TVDI). In order to express the negative correlation between NDVI and Ts more clearly, researchers simplified VITT as the Ts-NDVI triangle space (the Ts-NDVI space) (Liu et al. 2008; Carlson 2007; Price 1990) (Fig. 1). Researchers have monitored regional soil moisture using TVDI based on various remote sensing data, such as AVHRR (Rhee et al. 2010; Huber and Fensholt 2011), MODIS
(Chen et al. 2006; Caccamo et al. 2011), Lansat TM (Gao et al. 2011), and so on.

The Ts-NDVI space is easily affected by many factors, such as soil moisture, vegetation cover, quality of remote sensing data, and so on. These factors may lead to large differences in different periods, including the unstable dry/wet edges, which could not clearly express the theoretical edges of the space (Rahimzadeh et al. 2012). Thus, a stable Ts-NDVI space is required for a long-term regional drought monitoring. However, studies on the long-term regional soil moisture monitoring mainly focused on the models established by single time of remote sensing data or the comparison of a variety of drought index (Gao et al. 2011; Dogan et al. 2012; Du et al. 2013). Yu et al. (2011) suggested that if the vegetation did not change greatly, based on years of remote sensing data, the general Ts-NDVI space could be established, which would provide a more stable dry/wet edges, and the edges would be closest to the theoretical edges.

The Mongolian Plateau, as the largest arid and semiarid Plateau in Northern hemisphere, plays an important role in the climate changes and sustainable development of the ecological environment in Northeast Asia and East Asia (Han et al. 2011; Wang and Feng 2013; Liu et al. 2013). Studies suggest that the vegetation degradation in the Mongolian Plateau would affect the regional atmospheric circulation (Xue 1996; Liu et al. 2013). The vegetation degradation in the north China and south Mongolia may lead to the temperature increase in these regions and the temperature decrease in Central China; moreover, it would also result in the precipitation reduction in the north China and the precipitation increase in the Yangtz-Huaihe River Basin in China (Zhang et al. 2005; Wang and Feng 2013). Due to the low precipitation, diverse
Fig. 1 The Ts-NDVI triangle space (Sandholt et al. 2002)

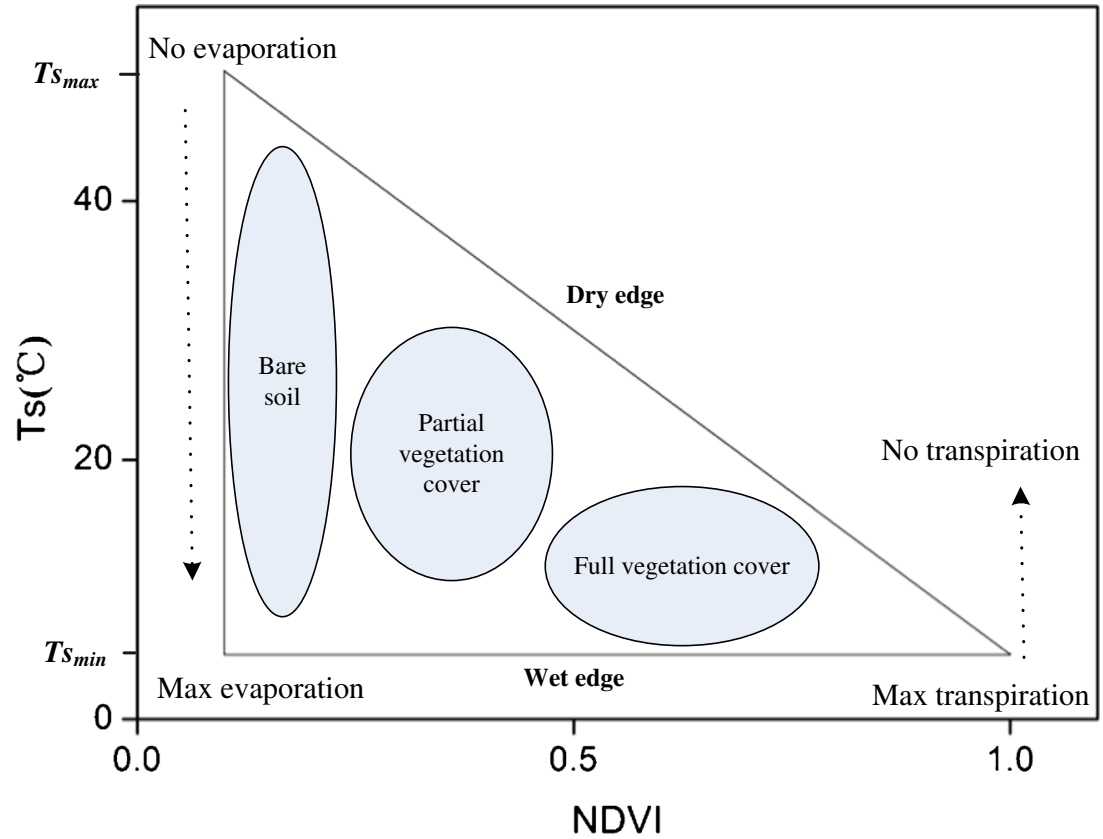


Land Use/Land Cover (LUCC), fragile ecological system, and unfavorable climate conditions, the Mongolian Plateau is considered to be an important dust source for global dust release (Zhang et al. 1996; Li and Liu 2012). In the past 50 years, because of lacking of a long-term development plan and consciousness of sustainable development, the excessive exploitation, utilization, and consumption of resources have resulted in many ecological environment problems in this region. Drought is a serious natural disaster in the Mongolian Plateau (Wang et al. 2008a, b), and aridification was obvious in the 21st century (Li and Liu 2012). Additional climate disasters, such as the reduced snow cover (Sachula et al. 2012), grassland degradation (Wang et al. 2013), desertification (Zhang et al. 2005), and frequent dust storms, have occurred. The China-Mongolia border has become a region, where the most severe and frequently continuous droughts occur (Shi and Liu 2012). There would be great scientific significance to monitor long-term drought variations in the Mongolian Plateau. However, former studies mainly focused on drought monitor in Northwest China (Yang et al. 2011), North China (Bi et al. 2011), and some regions of the Mongolian Plateau (Tian et al. 2012). Studies focused on the drought variations in the whole Mongolian Plateau have relatively lack of reports.

In this paper, using the long-term remote sensing data MODIS NDVI in 2000-2012, the authors develop a general Ts-NDVI space to estimate soil moisture in the Mongolian Plateau. Based on measured data, the relationship between TVDI and the soil moisture or precipitation is analyzed. Moreover, the spatiotemporal variations of the TVDI are studied and finally, the spatiotemporal variations of aridification in the Mongolian Plateau are deeply explored.

\section{Materials and methods}

\section{The study area}

The Mongolian Plateau $\left(87^{\circ} 40^{\prime} \sim 122^{\circ} 15^{\prime} \mathrm{N}, 37^{\circ} 46^{\prime} \sim 53^{\circ}\right.$ $08^{\prime} \mathrm{E}$ ) belongs to the inland plateau in Asia. The Eastern side is the Great Khingan Mountains; the western side is the Altai Mountains; the northern side is the Sayan Ridge, Kent Hill, Yabuluonuo; and the southern side is the Yinshan Mountains. Overall, the northwestern plateau is mainly covered by the mountains; the southwestern plateau is mainly covered by the Gobi desert. There is a large area of hilly grassland in the middle and eastern part. The elevation decreases gradually from west to east, with an average value of $1580 \mathrm{~m}$. The north plateau is affected by the water vapor from the Arctic Ocean, and the eastern part is affected by the water vapor from the Pacific Ocean. The annual precipitation is approximately $300 \sim 400 \mathrm{~mm}$, and it decreases from north to south and east to west. In South Mongolia, the annual precipitation is almost less than $200 \mathrm{~mm}$. The vegetation cover from north to south consists of forest, forest steppe, typical steppe, desert steppe, the Gobi desert, and typical steppe. This paper chose the Inner Mongolia Autonomous Region, Mongolia and the Tuva Republic as the study area. The total area of the study area is about $297.36 \times 10^{4} \mathrm{~km}^{2}$ (Fig. 2).

\section{Data and processing}

\section{MODIS/Terra NDVI products}

MODIS/Terra NDVI products (1-km MOD11A2 and 1-km MOD13A2) included in the study are obtained from the EOS data Gateway (NASA-EOS 2006). The MOD11A2 product (global 8-day $1 \mathrm{~km}$ surface temperature/emissivity data) includes the data from the 65 th day, 2000 to the $353 \mathrm{rd}$ day, 2012. The MOD13A2 product (global $1 \mathrm{~km} \mathrm{16-day} \mathrm{veg-}$ etation index data) includes the data from the 49th day, 2000 to the $353 \mathrm{rd}$ day, 2012. To unify the resolution, the 16-day surface temperature/emissivity data are calculated from the mean values of the 8-day data.

\section{Measured soil moisture data set}

The 10-day measured soil moisture data set is obtained from the China Meteorological Science Data Sharing Service (http://cdc.cma.gov.cn/home.do). The data set includes the $10-\mathrm{cm}$ relative soil moisture of the agrometeorological stations in the Inner Mongolian Autonomous Region from January 2000 to October 2012.

\section{The land use/land cover data}

The Land Use/Land Cover (LUCC) data (500 m) of 2001, 2005, and 2009 are collected from the National Science and Technology Basic Conditions Platform earth system science data sharing platform. The main LUCC types are forest, shrub land, grassland, cropland, bare land, construction land, wet land, and others (water area) (Fig. 3).

\section{The observed meteorological data}

The observed meteorological data (2000-2010), including the monthly precipitation data, is obtained from the World Meteorological Organization (WMO) World Weather Watch Program. There are about 60 meteorological stations available in the Mongolian Plateau. The annual precipitation data is the cumulative precipitation in the growing season (AprilOctober). 


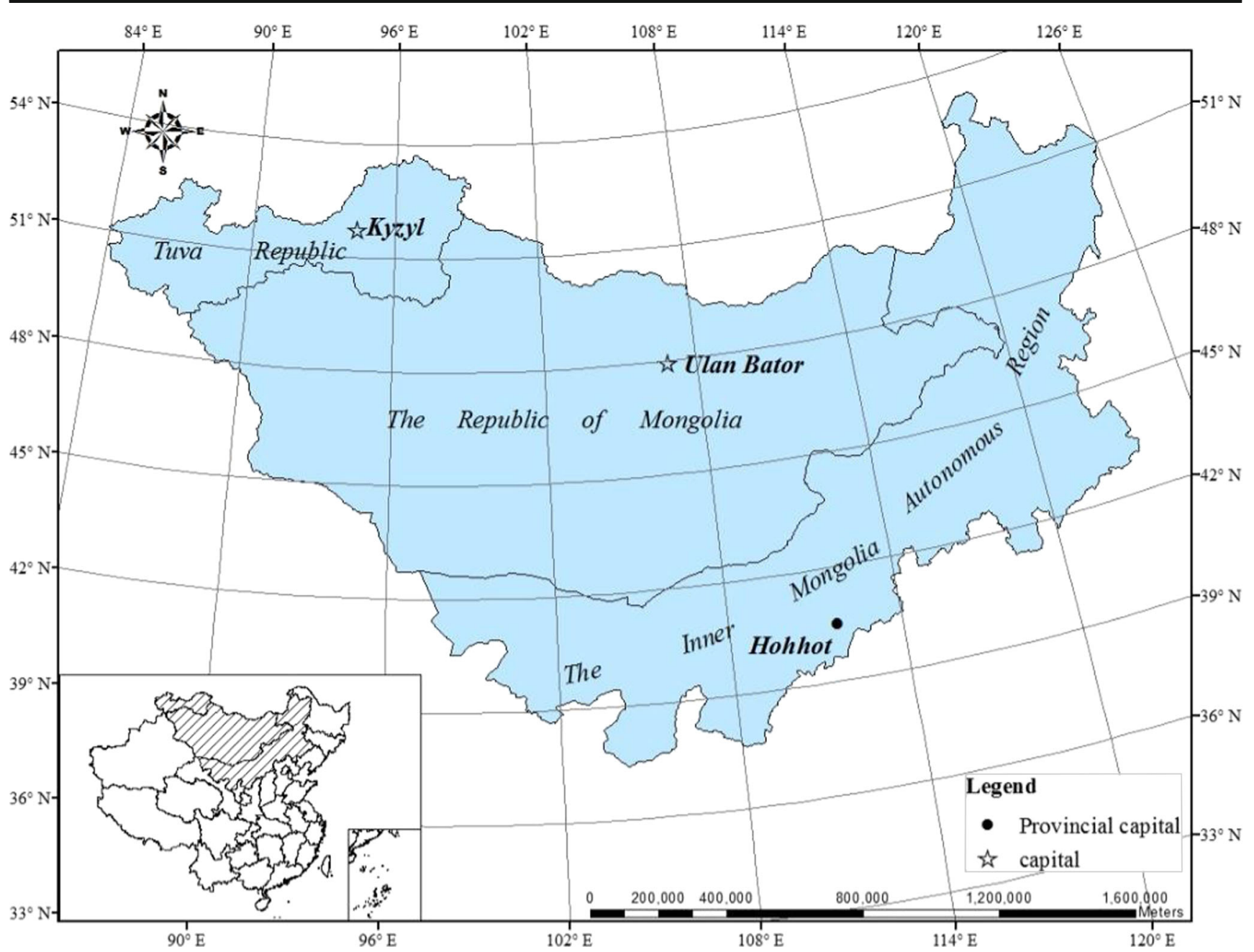

Fig. 2 The study area

Fig. 3 The Land Use/Land Cover (LUCC) in the Mongolia Plateau in 2001, 2005, and 2009
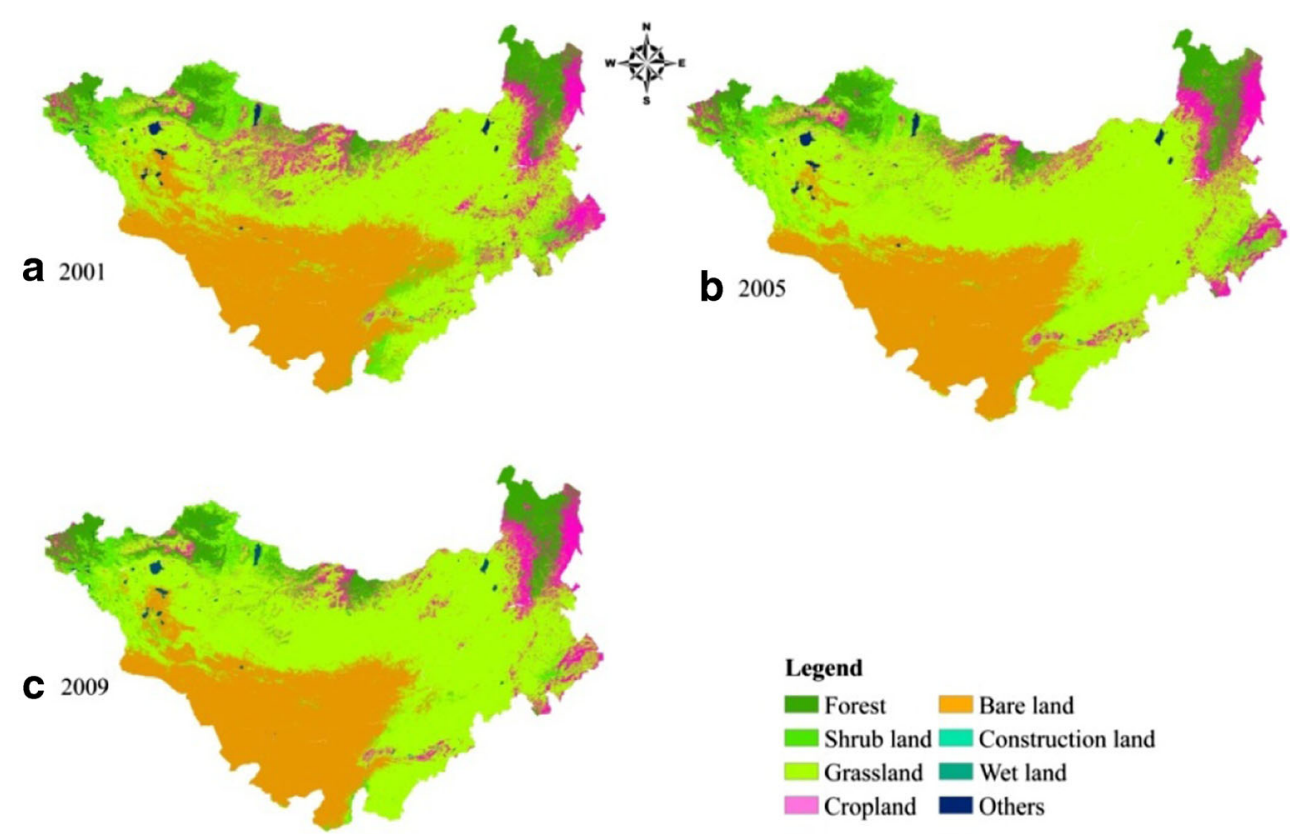

Legend

Forest Bare land

$\square$ Shrub land Construction land

Grassland Wet land

Cropland Others 


\section{The methods}

\section{The establishment of the general Ts-NDVI space}

Under certain geographical climatic and atmospheric conditions, the effects of soil moisture, evapotranspiration on Ts are larger than those of the net solar radiation absorbed by the land surface on the Ts (Sandholt et al. 2002). If the total vegetation cover does not change to a large degree, the general NDVI-Ts triangle space could be combined using years of remote sensing data over the same period. This method could improve the traditional Ts-NDVI space established by one single satellite data and improve the stability of the dry/wet edges, which would be more suitable for a long-term soil moisture monitoring study.

The combination steps of the general Ts-NDVI space are as follows (Fig. 4): (1) for a period of observation, the annual TsNDVI space is extracted by the remote sensing data of every year: with small intervals of NDVI value (0.001), the corresponding maximum or minimum Ts for every NDVI value is respectively obtained by using the maximum value composite method or the minimum value composite method. The dry edge is constituted by the maximum Ts values, and the wet edge is constituted by the minimum Ts values. (2) The combination of the general Ts-NDVI space: with the same interval NDVI value (0.001), by using the maximum value composite method or the minimum value composite method, the perennial maximum or minimum Ts for every NDVI value is respectively obtained from the Ts value in the dry or wet edge extracted above. The general dry edge is constituted by the perennial maximum Ts values, and the general wet edge is constituted by the perennial minimum Ts values. They could be calculated by the equations as follows:

$$
\begin{aligned}
& T s_{\mathrm{we}_{i}}=a_{1}+b_{1} \times I_{N D V I_{i}} \\
& T s_{d r y_{i}}=a_{2}+b_{2} \times I_{N D V I_{i}}
\end{aligned}
$$

where, $I_{N D V I_{i}}$ is the $N D V I$ value of the pixel $i ; T s_{\mathrm{wet}_{i}}$ is the corresponding minimum Ts value of very NDVI value (wet edge); $T s_{d r y_{i}}$ is the corresponding maximum Ts value of very NDVI value (dry edge); $a_{1}, a_{2}, b_{1}$, and $b_{2}$ respectively means the intercepts and the slopes of the wet and dry edges in the general Ts-NDVI space.

\section{Definition of the temperature vegetation dryness index}

Providing the design basis for VITT, different vegetation indexes such as NDVI, the airborne normalized difference vegetation index (ANDVI), the modified soil-adjusted vegetation index (MSAVI), and the soil-adjusted vegetation index (SAVI) may have different relationships with Ts (Heim 2002; Keyantash and Dracup 2002). Sandholt et al. (2002) reported that the simplified Ts-NDVI triangle space may exhibit the soil moisture contours reflecting the spatial patterns of the

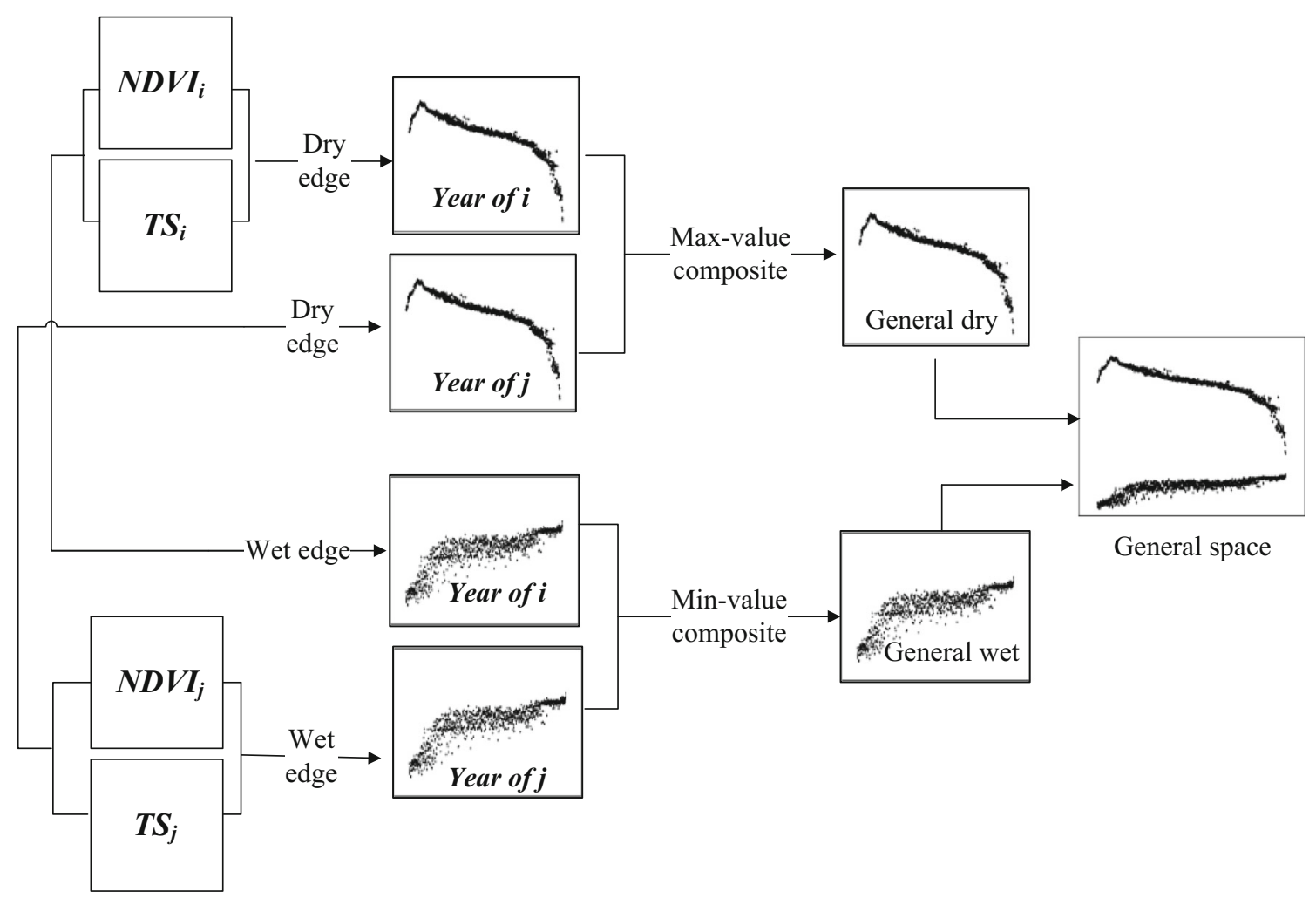

Fig. 4 Flow chart of composing the general Ts-NDVI space 
VITT, which led to the definition of the TVDI as expressed below:

$\mathrm{TVDI}=\frac{T s^{-}-T s_{w e t}}{T s_{d r y}-T s_{w e t}}$

where $T s_{d r y}$ is the corresponding maximum Ts value of very NDVI value (dry edge), $T S_{\text {wet }}$ is the corresponding minimum Ts value of very NDVI value (wet edge).

The slope of TVDI

Linear regression analysis could be used to analyze the change in every grid, Stow et al. (2003) has used this method to estimate the greenness rate of change (GRC). This study uses this method to simulate the multiannual variation trends of the TVDI. The formula is

$\Theta_{\text {slope }} \mathrm{TVDI}=\frac{n \times \sum_{i=1}^{n} i \times T V D I_{i}-\sum_{i=1}^{n} i \sum_{i=1}^{n} i \times T V D I_{i}}{\sum_{i=1}^{n} i^{2}-\left(\sum_{i=1}^{n} i\right)^{2}}$ where, $i$ is of the year, $T V D I_{i}$ is the mean $T V D I$ of the year $i$. The linear regression trend line is the whole multiannual change trend of the simulated TVDI. The confidence level of the regression equation is significant (95\%). The regression trend line describes that the changes occur during the study period. If $\Theta_{\text {slope }}>0, T V D I$ during the study period increased, and vice versa.

\section{Results and discussion}

\section{The improvement of the Ts-NDVI space}

Figure 5 presents the single-time Ts-NDVI spaces of every year and the general Ts-NDVI space. It is indicates the instabilities of the single-time Ts-NDVI spaces; there were some differences among the dry/wet edges in different years. Taking the year of 2002, 2005, and 2008 as an example, the dry edge and wet edge was closer, which had much difference with the dry edge and wet edge in the general Ts-NDVI space (Fig. 5). Moreover, there were some points with a lower NDVI scattered outside of the wet edge in the single time spaces,
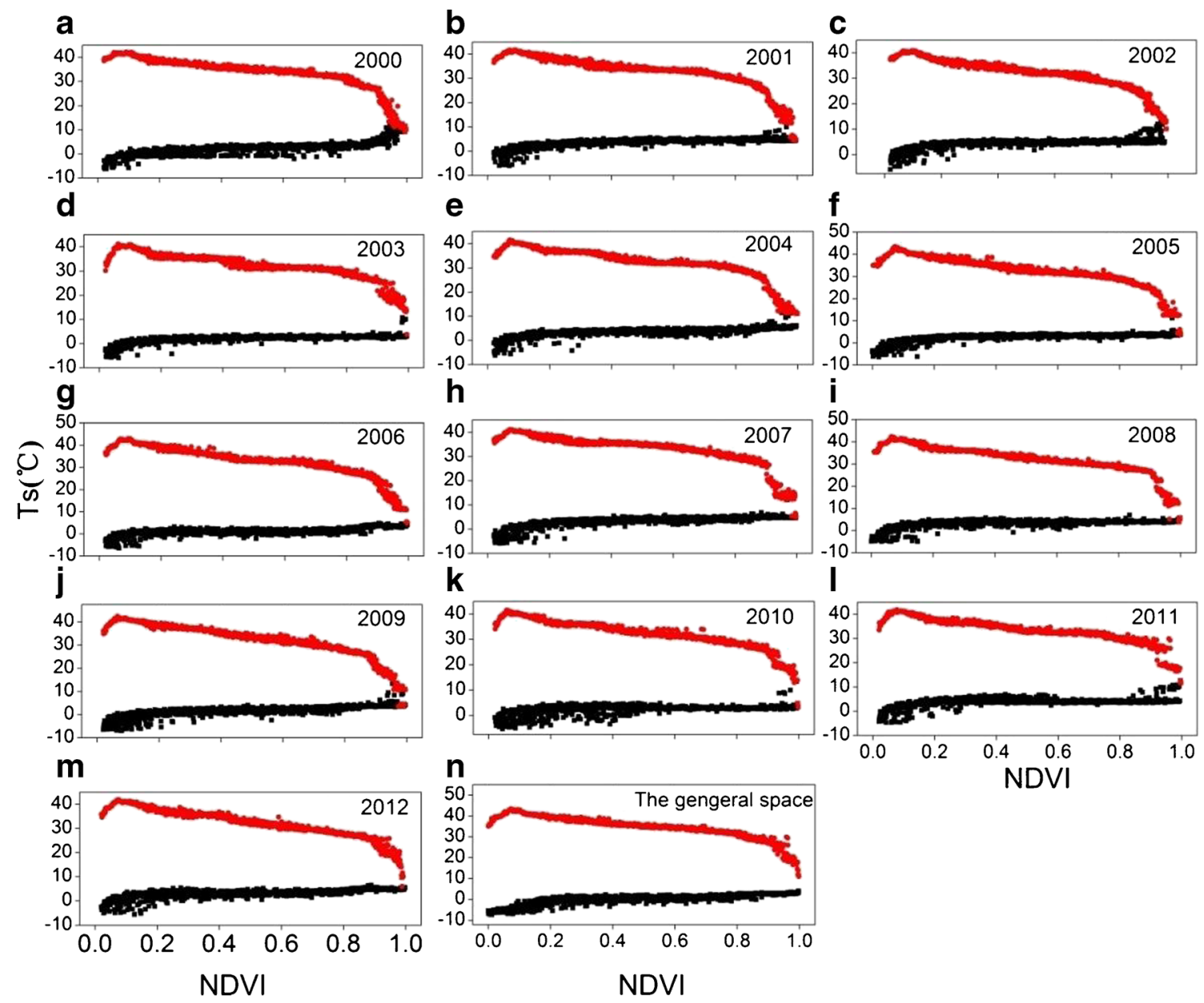

Fig. 5 The single-time Ts-NDVI space of every year and the general Ts-NDVI space $(n)$ 
which would reduce the accuracy of the linear fit in the wet edge.

In the general, Ts-NDVI spaces, the Ts values in dry edge were commonly higher than that in the single time spaces, and the Ts values in wet edge were commonly lower than that in the single time spaces. In addition, the boundaries of the general Ts-NDVI spaces were clearer than those of the single time spaces, the number of abnormal samples also reduced significantly in the general Ts-NDVI spaces (Fig. 5). In the area with lower NDVI values, the differences in Ts of dry edge and wet edge were more significant; in the area with higher NDVI values, the differences in Ts of dry edge and wet edge were small, the dry edge and the wet edge gradually merged, a closed triangle space forms.

The correlation between the TVDI based on the general or the single-time Ts-NDVI space and the measured $10-\mathrm{cm}$ soil moisture

Base on the general Ts-NDVI space, and Eq. 6, the 16-day TVDI (1 km) during 2000-2012 were inverted in the study area. The ground validation data were the $10-\mathrm{cm}$ measured soil moisture (10-day) obtained from the China Meteorological Science Data Sharing Service. To match the time resolution of MODIS dataset, the measured 10-day soil moisture data was interpolated as the 16-day time series data. To match the spatial resolutions of the remote sensing data, the pixels with the NDVI variance $<0.005$ and the Ts variance $<2{ }^{\circ} \mathrm{C}$ were obtained by the $3 \times 3$ pixel window. The mean TVDI values in the $3 \times 3$ pixel window were calculated to establish the linear relationship with the measured $10-\mathrm{cm}$ soil moisture data.

There was significant negative relationship between TVDI and the measured $10-\mathrm{cm}$ soil moisture. The correlation index in every year was greater than $0.55(P<0.01)$ (Fig. 6), indicating that the TVDI could reflect the variation tendency of soil moisture, and it could be chosen as a suitable indicator to monitor drought and aridification. The results show that in 2002, 2005, and 2008, the correlations of the general TsNDVI space were better than that of the single time spaces, but there were no obvious differences of the correlation in other years (Table 1). In Fig. 6, it could be explored that, in the above mentioned years, there were obvious differences of the Ts in dry or wet edge between the general and the single time spaces. It would be included that, if the single time space shows an unstable condition, and there are obvious differences between the single time space and the general space, then the inverted results of the general space would be more meaningful. Otherwise, if the single time space shows a perfect structure, then there would be no differences between the inverted results of the single time space and the general space.

The correlations between the TVDI and the measured 10$\mathrm{cm}$ soil moisture showed major interannual fluctuation. It would be very different in the spatial and time resolutions between remote sensing data and the measured $10-\mathrm{cm}$ soil moisture data. Although, the time interpolation and spatial buffer has been processed, the differences could not be eliminated completely. In addition, the differences of the atmospheric conditions, the sun angle, and the observation angle of remote sensing data in different years also affect the monitoring results.

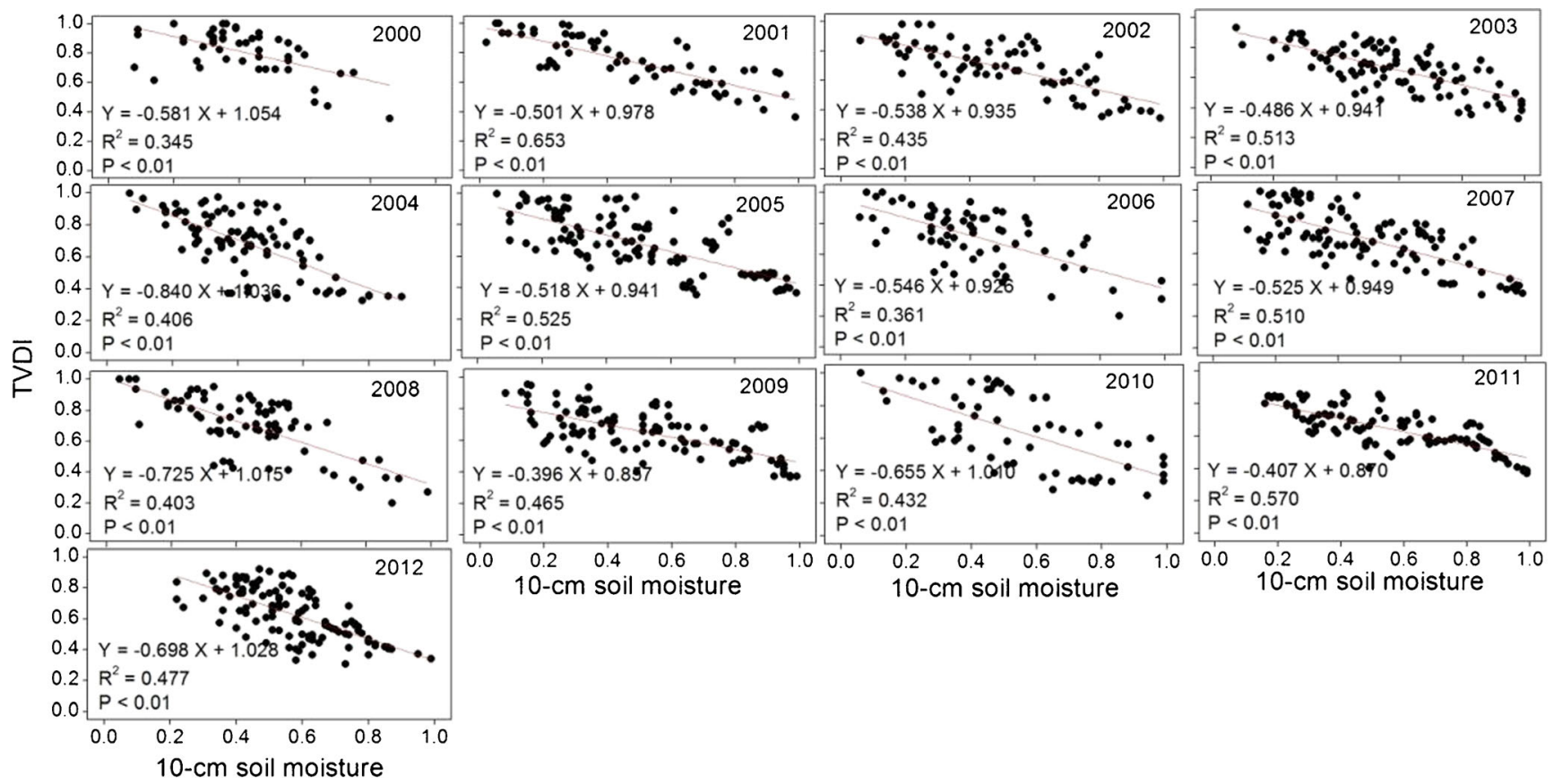

Fig. 6 The scatters of the 10-cm soil moisture and TVDI based on the general Ts-NDVI space 
Table 1 The linear correlation coefficients between the TVDI based on the per-improvement/ post-improvement Ts-NDVI space and the measured $10-\mathrm{cm}$ soil moisture

\begin{tabular}{llllllll}
\hline Year & 2000 & 2001 & 2002 & 2003 & 2004 & 2005 & 2006 \\
\hline The number of samples & 49 & 66 & 74 & 99 & 90 & 116 & 67 \\
$R^{2}$ of the general space & 0.345 & 0.653 & 0.435 & 0.513 & 0.406 & 0.525 & 0.361 \\
$R^{2}$ of the single time space & 0.346 & 0.649 & 0.356 & 0.511 & 0.408 & 0.520 & 0.358 \\
Year & 2007 & 2008 & 2009 & 2010 & 2011 & 2012 & \\
The number of samples & 106 & 77 & 109 & 65 & 104 & 122 & \\
$R^{2}$ of the general space & 0.510 & 0.403 & 0.465 & 0.432 & 0.570 & 0.477 \\
$R^{2}$ of the single time space & 0.498 & 0.321 & 0.461 & 0.429 & 0.567 & 0.453 \\
\hline
\end{tabular}

The coefficients in the table are the confidence level of 0.9 , respectively
The correlation between the TVDI based on the general or the single time Ts-NDVI space and the cumulative precipitation

Figure 7 delineates the linear correlation between the cumulative precipitation and TVDI based on the general Ts-NDVI space. To match the spatial resolutions of the remote sensing data, the pixels with the NDVI variance $<0.005$ and the Ts variance $<2{ }^{\circ} \mathrm{C}$ are obtained by the $3 \times 3$ pixel window. The mean TVDI values in the $3 \times 3$ pixel window are calculated to establish the linear relationship with the measured cumulative precipitation (April-October). There is obvious negative correlation between TVDI and the cumulative precipitation (Fig. 7), which could indicate that, in the regions with low precipitation $(<400 \mathrm{~mm})$, precipitation would determine the drought degrees. Studies show that, in the regions with high precipitation, besides precipitation, other factors affecting the regional energy and water balance would also influence the occurrence of drought (Qi 2004).

Table 2 expresses the correlation between the cumulative precipitation and the TVDI based on the general or the singletime Ts-NDVI space. In 2002, 2005, and 2008, the correlations in the general Ts-NDVI space were better than that in the single time spaces, but there were no obvious differences on the correlation in the other years (Table 2), which would indicate the similar results mentioned in the "The correlation between the TVDI based the general or the single time Ts-NDVI space and the measured $10-\mathrm{cm}$ soil moisture" section: if the single time space shows an unstable condition, and there are obvious differences between the single time spaces and the general spaces, then the inverted results based on the general spaces would be more meaningful. Otherwise, if the single time space showed a perfect structure, then there would be no differences between the inverted results based on the single
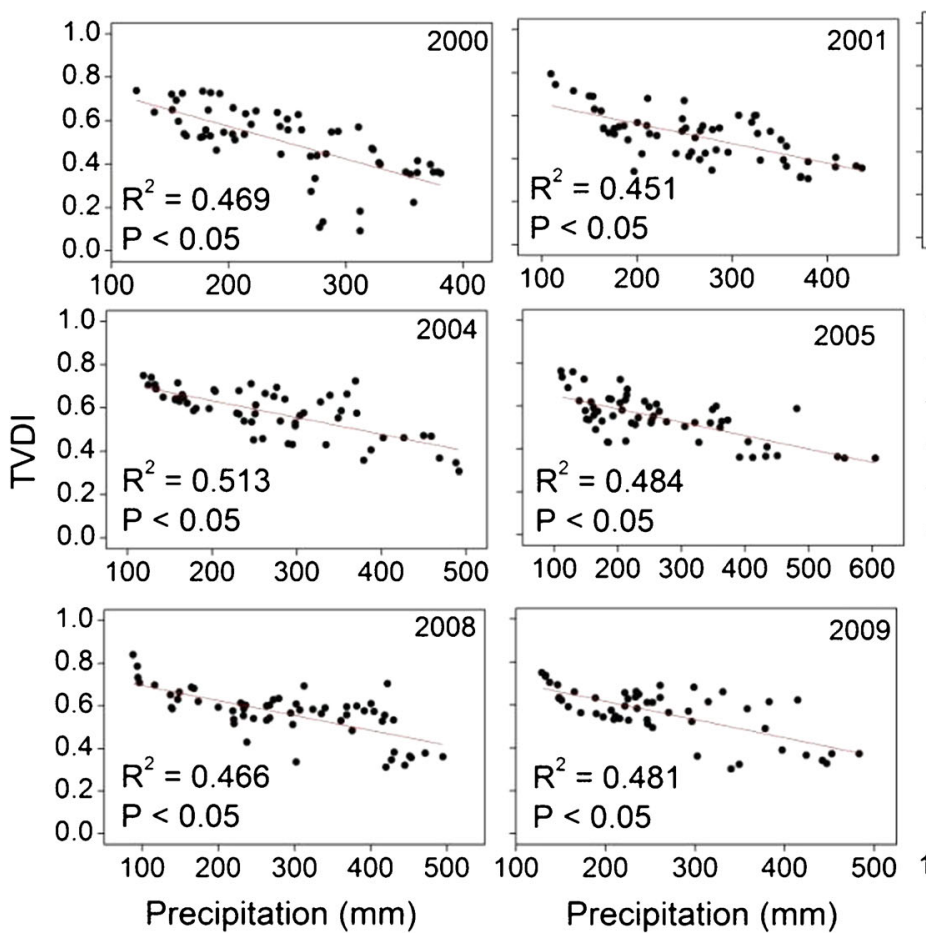
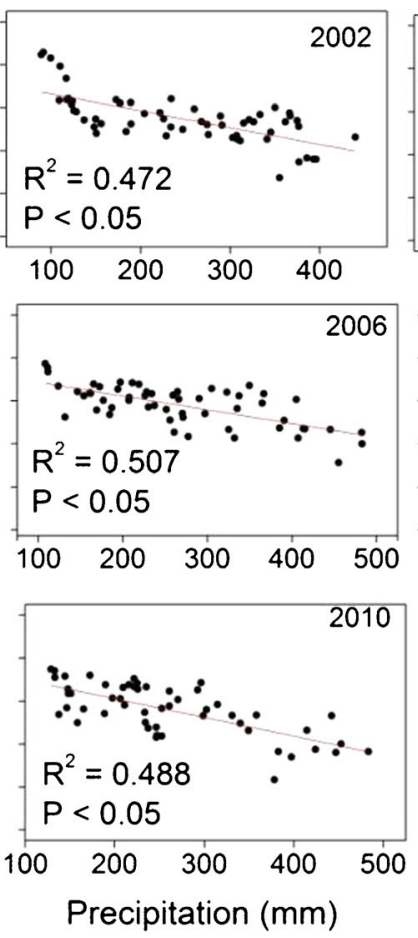

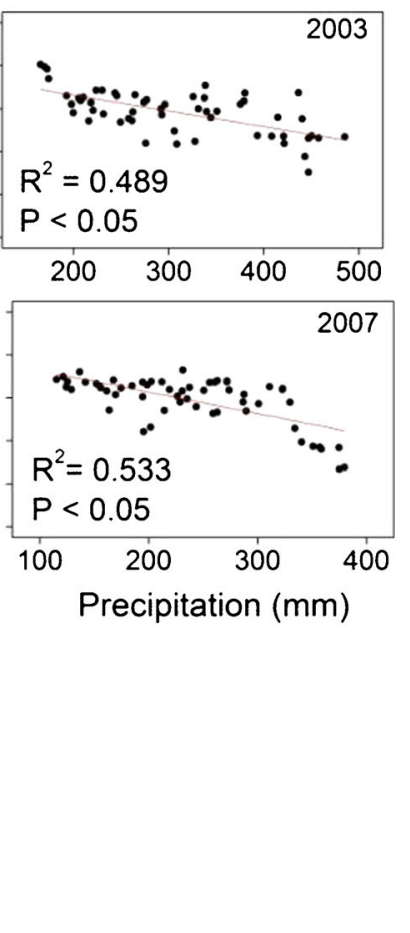

Fig. 7 The scatters of the cumulative precipitation and TVDI based on the general Ts-NDVI space 
Table 2 The linear correlation coefficients between the TVDI based on the per-improvement/ post-improvement Ts-NDVI space and the cumulative precipitation

\begin{tabular}{lllllll}
\hline Year & 2000 & 2001 & 2002 & 2003 & 2004 & 2005 \\
\hline$R^{2}$ of the general space & 0.469 & 0.451 & 0.472 & 0.489 & 0.513 & 0.484 \\
$R^{2}$ of the single time space & 0.452 & 0.446 & 0.435 & 0.465 & 0.506 & 0.477 \\
Year & 2006 & 2007 & 2008 & 2009 & 2010 & \\
$R^{2}$ of the general space & 0.507 & 0.533 & 0.466 & 0.481 & 0.488 & \\
$R^{2}$ of the single time space & 0.506 & 0.529 & 0.432 & 0.459 & 0.489 & \\
\hline
\end{tabular}

The coefficients in the table are the confidence level of 0.5 , respectively time spaces and the general spaces. In addition, the correlations between the TVDI and the cumulative precipitation also showed major interannual fluctuations, which would have resulted from the influence of the quality and the atmospheric condition for the satellite observation.

\section{The spatiotemporal development of TVDI}

This paper classified TVDI into five levels (Table 3). The results show that TVDI can reflect the onset, duration, extent, and severity of drought in the study area (Fig. 8). TVDI in the Mongolian Plateau presented a zonal distribution with changes in vegetation types, vegetation cover, and latitude. TVDI became lower in the areas with higher latitude, higher vegetation cover, or well-growing vegetation, which would indicate higher soil moisture and little drought events in these areas; in contrast, the soil moisture would be possibly lower in the regions with lower latitude, lower vegetation cover, or poorly growing vegetation, indicating frequent drought events in these areas (Fig. 8). The wet and extremely wet levels mainly distributed in the Greater Khinggan Mountains in Inner Mongolia, the eastern and western regions in the Tuva Republic, and the north Mongolia mainly covered by forest. The normal level mainly distributed in the higher vegetationcovered grassland in the north and west Mongolia, the surrounding areas of the Greater Khinggan Mountains, and the cropland in the east and middle Inner Mongolia. The extremely dry and dry levels mainly distributed in the lower vegetation-covered grassland, desert, and Gobi in the south Mongolia, the east, west and middle Inner Mongolia. There were close relationships among the spatial distribution in drought, climatic zone, and precipitation. Overall, drought was widely spread in the Mongolian Plateau, which would mainly result from the dry climate and low covered vegetation. The low precipitation, high temperature in the summer, and the low temperature in the long-term winter may also lead to widely spread drought in the Plateau.

Figure 9 shows that, during 2000-2012, TVDI increased mainly in west Tuva, west and north Mongolia, and southeast Inner Mongolia, which meant the decreasing soil moisture and the aggravated drought. TVDI decreased mainly in south Mongolia, south and southwest Inner Mongolia, and the cropland in east Inner Mongolia. In addition, in the Greater Khinggan Mountains, the soil moisture decreased in 2000 2012. In the grassland of west and middle Mongolia, where the meadow mainly distributes, the soil moisture showed a continued decrease. It could reveal that, due to overgrazing, the vegetation over decreased in these regions, which would result in the decrease of soil moisture. Table 4 shows that, in 2000-2012, the aggravated drought area was $139.86 \times 10^{4} \mathrm{~km}^{2}$, and the alleviated drought area was $66.35 \times 10^{4} \mathrm{~km}^{2}$. It would indicate that the drought aggravated in the Mongolian Plateau during 2000-2012. The area proportion of every level varied in one growth season. The extremely wet, wet, and normal area increase slightly from April to August and decrease in September and October. In April, drought is widespread in the Plateau (Fig. 8). From May to August, with the increasing temperature and precipitation, vegetation begins to sprout and grow, the soil moisture and humid area keep on increasing, and the aridification appeared alleviated. In September and October, with the end of rainy season and growth season, the precipitation decreases, the dry and extremely dry level show a slight increase. But compared with April, drought in September and October was lighter. Although there was drought during the growth season, drought during the early growth season was more serious than that at the end of growth season. In the beginning of growth season, more water is needed for the vegetation germination, but the precipitation is relatively low, which would be responsible for these results.

Table 3 TVDI classification standard of drought in the Mongolia Plateau

\begin{tabular}{llllllll}
\hline & \multicolumn{2}{c}{ The humid area } & & The normal area & & \multicolumn{2}{c}{ The arid area } \\
\cline { 2 - 6 } & Extremely wet & Wet & & Normal & & Dry & Extremely dry \\
\hline The classification of TVDI & {$[0,0.2]$} & {$[0.2,0.4]$} & & {$[0.4,0.6]$} & {$[0.6,0.8]$} & {$[0.8,1.0]$} \\
\hline
\end{tabular}


Fig. 8 The spatial distribution of the annual TVDI in 2000-2012

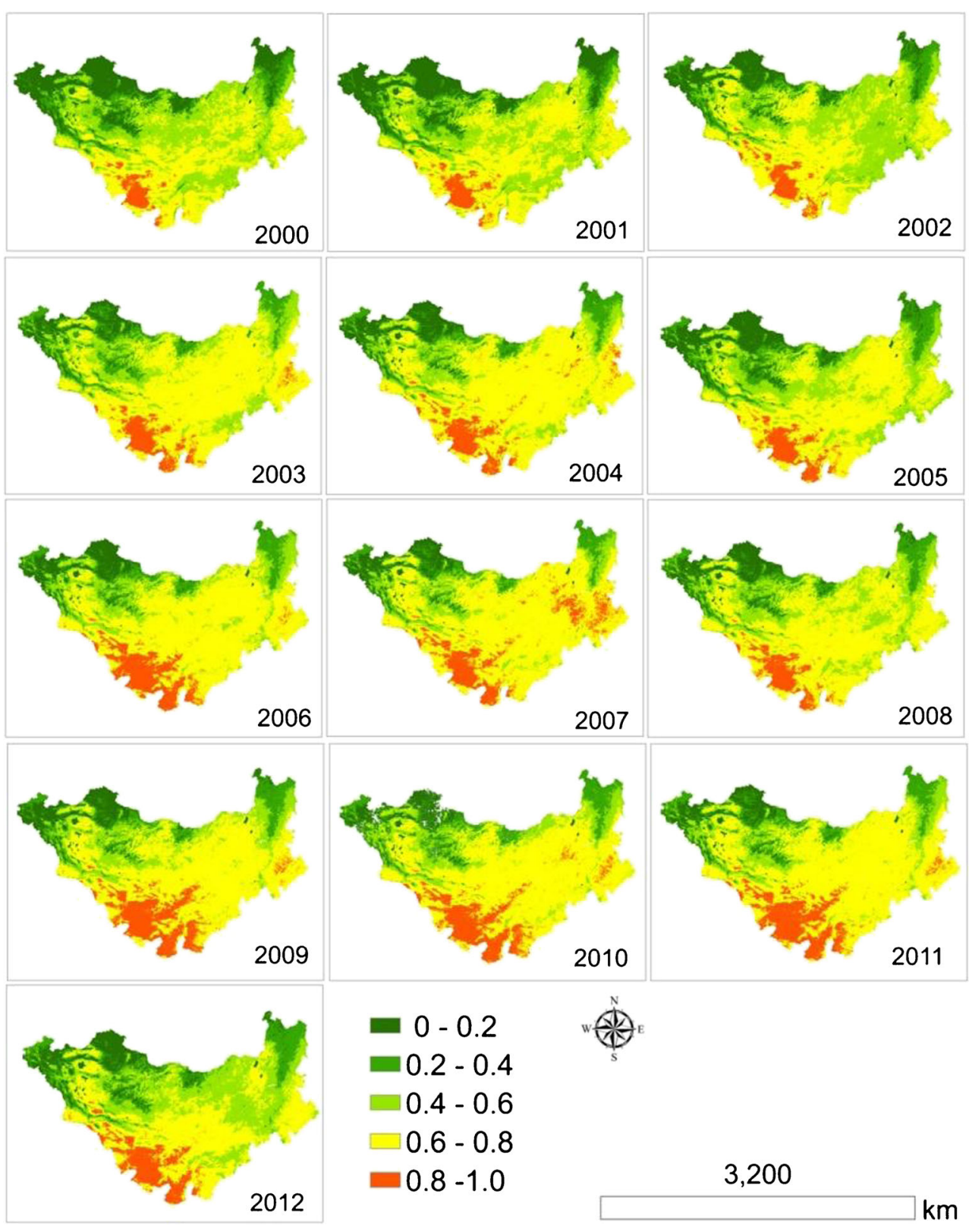

\section{The variation of the aridification in the Land Use/Land} Cover

There is a close relationship between soil moisture and LUCC (Fu et al. 1999; Huang et al. 2005; Wang et al. 2010; Rahimzadeh et al. 2013). The soil moisture could affect the growth of plants, while the LUCC and vegetation cover could also affect the distribution and content of water in soil (Fu et al. 1999; Chen et al. 2006). The LUCC in the Plateau is dominated by grassland and bare land (Fig. 2, Table 5). The grassland mainly distributes in the western, northern, and southeastern regions in the Plateau, accounting for about $50.82 \%$ of the total area. The bare land mainly distributes in the southwestern regions in the Plateau, accounting for about
$27.10 \%$. In the north Plateau, the forest $(8.14 \%)$ is wildly spread. Shrub land accounted for about $4.89 \%$ of the Plateau area. Cropland $(8.35 \%)$ mainly distributes in the Inner Mongolia.

The TVDI calculated in the paper is expected to show the water deficit for the region from low (bare soil) to high (full vegetation cover) NDVI values. Comparing the TVDI values and LUCC types map (Fig. 2 and Fig. 8) show that the TVDI values were lower in forest and shrub land and higher in grassland, bare land, construction land, and crop land. Forest and shrub land were dominated by the wet and extremely wet levels, the normal level was the second one, and the dry and extremely dry levels were the least. In the forest, the wet/ extremely wet area and the normal area averagely accounted 
Fig. 9 The variations (slope) of TVDI in 2000-2012

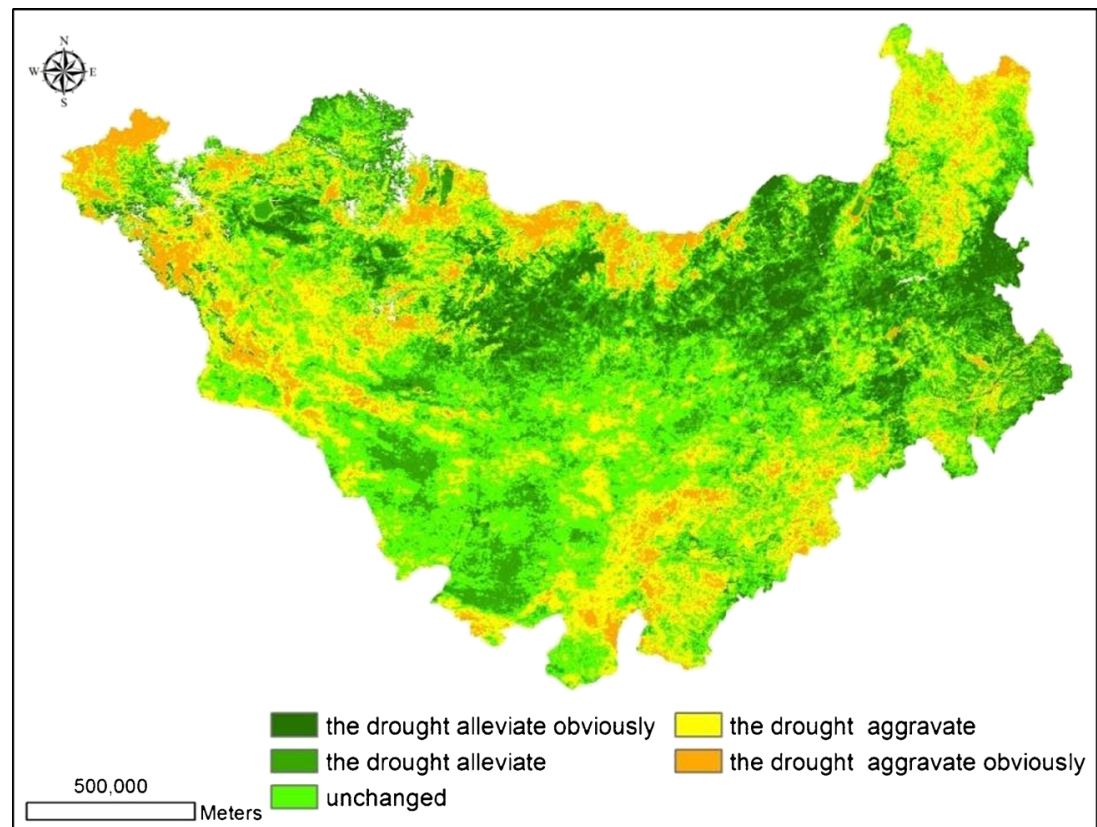

for about 89.86 and $9.89 \%$ of the total area; the dry and extremely dry area only accounted for about $0.56 \%$. In shrub land, the proportion of the wet/extremely wet, normal, and the dry/extremely dry area account for about 73.00, 10.40, and $16.60 \%$ of the total area, respectively. As expected, there was almost no drought in the forest. The dry/extremely dry area proportion in shrub land was obviously larger than that in the forest, which would suggest that there were some droughts in the shrub land. In grassland, bare land and construction land, the dry/extremely dry area accounted for the largest proportion, followed by the normal level, and the wet/extremely wet was the least one. Overall, there were obvious differences in the TVDI level allocation in different LUCC types; aridification was the most serious in bare land (about $80 \%$ of the area suffers drought), followed by construction land, and grassland. In construction land and grassland, about $53 \%$ of the area suffered drought. Based on the results obtained in the "The correlation between the TVDI based the general or the single time Ts-NDVI space and the measured 10-cm soil moisture" and "The correlation between the TVDI based the general or the single time Ts-NDVI space and the cumulative precipitation" sections, the TVDI was found to be in close negative agreement with precipitation and soil moisture; therefore, it can be inferred that changes in the TVDI are dependent on the water status in the study area. As cumulative precipitation for the growing season is higher in forest and shrub land than in the other LUCC types, it can be concluded that forest and shrub land have better water availability.

The dry/extremely dry area proportion in different LUCC types had few annual changes, but it had obvious monthly changes (Fig. 10), which mainly occurred between grassland and bare land in September and October. From April to August, the dry/extremely dry area proportion in grassland was obviously larger than that in bare land, and in September and October, the trend was the inverse. These results indicate that, at the end of the growth season, drought is relieved in some areas of grassland. The reasons for these results would be considered in two parts: (1) at the end of growth season, the drastically reduced precipitation results in more severe drought in bare land and (2) overgrazing may lead to the appearance of bare area in grassland and the increasing soil moisture evaporation. Therefore, in the early and peak of the growth season, short-term drought would occur in some areas of grassland. However, there are no explicit data to

Table 4 The area of the changed TVDI in the Mongolian Plateau in $2000-2012\left(\times 10^{4} \mathrm{~km}^{2}\right)$

\begin{tabular}{llllll}
\hline TVDI variation range & $\begin{array}{l}\text { Drought aggravate obviously } \\
<-0.2\end{array}$ & $\begin{array}{l}\text { Drought aggravate } \\
{[-0.2,-0.005]}\end{array}$ & $\begin{array}{l}\text { Unchanged } \\
{[-0.005,0.005]}\end{array}$ & $\begin{array}{l}\text { Drought alleviate } \\
{[0.005,0.2]}\end{array}$ & $\begin{array}{l}\text { Drought alleviate obviously } \\
>0.2\end{array}$ \\
\hline The Plateau & 46.59 & 93.27 & 91.15 & 51.56 & 14.79 \\
Inner Mongolia & 14.45 & 29.79 & 33.55 & 24.19 & 7.96 \\
Mongolia & 27.04 & 50.63 & 49.93 & 25.08 & 6.31 \\
Tuva & 5.1 & 12.85 & 7.67 & 2.29 & 0.52 \\
\hline
\end{tabular}


Table 5 The area and proportion of every LUCC type in the Mongolian Plateau $\left(\times 10^{4} \mathrm{~km}^{2}\right)$

\begin{tabular}{|c|c|c|c|c|c|c|}
\hline \multirow[t]{2}{*}{ Types } & \multicolumn{2}{|l|}{2001} & \multicolumn{2}{|l|}{2005} & \multicolumn{2}{|l|}{2009} \\
\hline & Area & Proportion & Area & Proportion & Area & Proportion \\
\hline Grassland & 134.38 & $45.24 \%$ & 161.49 & $54.37 \%$ & 157.02 & $52.86 \%$ \\
\hline Bare land & 88.45 & $29.78 \%$ & 74.03 & $24.92 \%$ & 79.03 & $26.61 \%$ \\
\hline Forest & 22.9 & $7.72 \%$ & 23.41 & $7.87 \%$ & 26.23 & 0.0884 \\
\hline Shrub land & 19.1 & $6.43 \%$ & 12.84 & $4.32 \%$ & 11.65 & $3.92 \%$ \\
\hline Cropland & 29.79 & $10.03 \%$ & 22.99 & $7.74 \%$ & 20.8 & $7.00 \%$ \\
\hline Construction land & 0.42 & $0.14 \%$ & 0.42 & $0.14 \%$ & 0.42 & $0.14 \%$ \\
\hline Wet land & 0.06 & $0.02 \%$ & 0.12 & $0.04 \%$ & 0.19 & $0.07 \%$ \\
\hline Others & 1.94 & $0.65 \%$ & 1.72 & $0.58 \%$ & 1.69 & $0.57 \%$ \\
\hline
\end{tabular}

explain this phenomenon; the causes and mechanism of this phenomenon would require an in-depth study.

\section{Conclusion}

Using the general Ts-NDVI space to invert TVDI is an effective method. If the single time Ts-NDVI space shows an unstable condition, and there are obvious differences between the single time space and the general space, the inverted results of the general space would be more meaningful. Otherwise, there would be no differences between the inverted results of the single time space and the general space. The TVDI calculated in the paper is expected to show the water deficit for the region from low (bare soil) to high (full vegetation cover) NDVI values, and it is found to be in close negative agreement with precipitation and soil moisture; changes in the TVDI are dependent on the water status in the study area.

From 2000 to 2012, drought was widely spread throughout the Mongolian Plateau. In the Mongolian Plateau, TVDI presented a zonal distribution with changes in LUCC types, vegetation cover, and latitude. TVDI became lower in the areas with higher latitude, higher vegetation cover, or well-growing vegetation, which would indicate higher soil moisture and little drought events in these areas; the soil moisture would be possibly lower in the regions with lower latitude, lower vegetation cover, or poorly growing vegetation, indicating frequent drought events in these areas. The dry level dominated in bare land, construction land, and grassland, and drought in bare land was the most serious. The wet level dominated in forest and shrub land, and there was almost no drought in forest. There were close relationship among the spatial distributions in drought, climatic zone, and precipitation. The low

a b

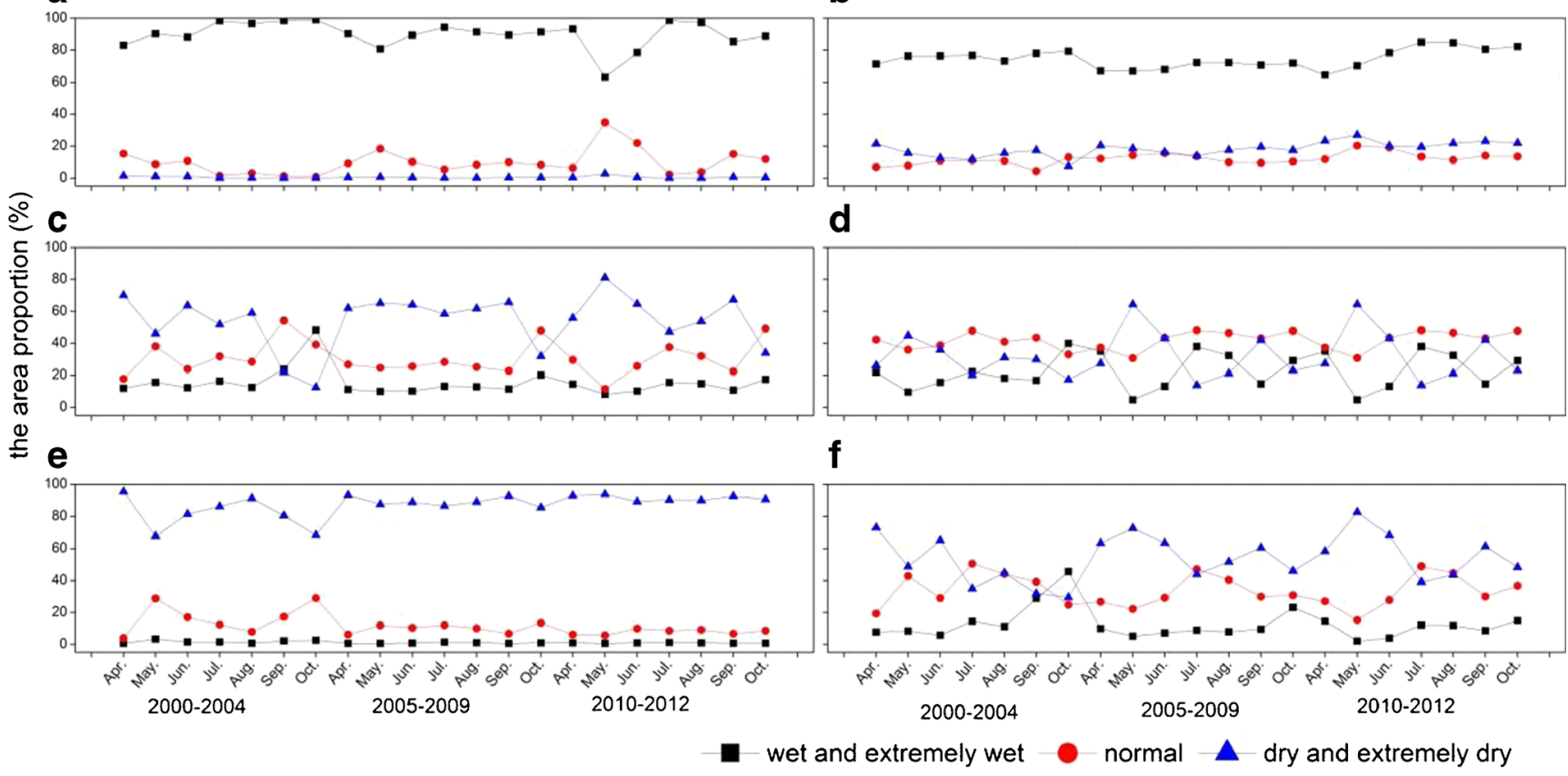

Fig. 10 The area proportion of different drought level in every LUCC (a forest; b shrub; $\mathbf{c}$ grassland; d cropland; e bare land; f construction land) 
precipitation, high temperature in the summer, and the low temperature in the long-term winter may also lead to the widely spread drought in the Plateau.

Acknowledgments The authors are grateful for the support by the National Key Basic Research and Development Program (973 Program) (Grant No.2013CB429905-04), the Key Deployment Project of the Chinese Academy of Sciences (Grant No.KZZD-EW-08), the youth fund from the National Natural Science Foundation of China (Grant No.41501477), and the special scientific research fund of forestry public welfare profession of China (Grant No. 201404304).

\section{References}

Anyamba A, Tucker CJ (2005) Analysis of Sahelian vegetation dynamics using NOAA-AVHRR NDVI data from 1981 to 2003. J Arid Environ 63(3):596-614

Bi LG, Yin S, Bao YL, et al. (2011) Research on the drought during the vegetation growth period of Inner Mongolia based on TVDI. J Anhui Sci 39(10):5945-5948

Caccamo G, Chilsholm LA, Bradstock RA, et al. (2011) Assessing the sensitivity of MODIS to monitor drought in high biomass ecosystems. Remote Sens Environ 115:2626-2639

Carlson T (2007) An overview of the triangle method for estimating surface evapotranspiration and soil moisture from satellite imagery. Sensors 7(8):1612-1629

Chandrasekar K, Sai MVRS (2015) Monitoring of late-season agricultural drought in cotton-growing districts of Andhra Pradesh state, India, using vegetation, water and soil moisture indices. Nat Hazards 75(2):1023-1046

Chen XL, Zhao HM, Li PX, Yin ZY (2006) Remote sensing image-based analysis of the relationship between urban heat island and land use/ cover changes. Remote Sens Environ 104:133-146

Dogan S, Ai B, Singh VP (2012) Comparison of multi-monthly rainfallbased drought severity indices with application to semi-arid Konya closed basin. Turkey J Hydrol 47-471:255-268

Du LT, Tian QJ, Tao Y, et al. (2013) A comprehensive drought monitoring method integrating MODIS and TRMM data. Int J Appl Earth Obs Geoinf 23:245-253

Fu BJ, Cheng LD, Ma KM (1999) The effect of land use change on the regional environment in the Yang Juangou catchment in the Loess plateau of China. Acta Geograph Sin 5(54):241-246

Gao Z, Gao W, Chang NB (2011) Integrating temperature vegetation dryness index (TVDI) and regional water stress index (RWSI) for drought assessment with the aid of LANDSAT TM/ETM+ images. Int J Appl Earth Obs Geoinf 13(3):495-503

Goetz SJ (1997) Multi-sensor analysis of NDVI, surface temperature and biophysical variables at a mixed grassland site. Int J Remote Sens 18(1):71-94

Han LJ, Atsushi T, Mitsuru T (2011) Effect of frozen ground on dust outbreaks in spring on the eastern Mongolian plateau. Geomorphology 129(3-4):412-416

Heim RR (2002) A review of twentieth-century drought indices used in the United States. Bull Am Meteorol Soc 83:1149-1165

Huang YL, Chen LD, Fu BJ, Wang YL (2005) Spatial pattern of soil water and its influencing factors in a gully catchment of the Loess plateau. J Nat Resourc 20(4):483-492

Huber S, Fensholt R (2011) Analysis of teleconnections between AVHRR-Based Sea surface temperature and vegetation productivity in the semi-arid Sahel. Remote Sens Environ 115:3276-3285

Jacoby GC, Rosanne DD, Davaajamts T (1996) Mongolian tree rings and 20th century warming. Science 273:771-773
Keyantash J, Dracup J (2002) The quantification of drought: an evaluation of drought indices. Bull Am Meteorol Soc 83:1167-1180

Kogan FN (1995) Application of vegetation index and brightness temperature for drought detection. Adv Space Res 15(11):91-100

Li XZ, Liu XD (2012) A modeling study on drought trend in the SinoMongolian arid and semiarid regions in the 21 st century. Arid Zone Res 3:262-272

Li XZ, Liu XD, Ma ZG (2004) Analysis on the drought characteristics in the main arid regions in the world since recent hundred-odd years. Arid Zone Res 21(2):97-103

Liu HZ, Wang BM, Fu CB (2008) Relationships between surface albedo, soil thermal parameters and soil moisture in the semi-arid area of Tongyu, Northeastern China. Adv Atmos Sci 25(5):757-764

Liu YL, Zhuang QH ,Chen M et al (2013) Response of evapotranspiration and water availability to changing climate and land cover on the Mongolian plateau during the 21st century. Glob Planet Chang 108: pp. 85-99

Malo AR, Nicholson SE (1990) A study of rainfall and vegetation dynamics in the African Sahel using normalized difference vegetation index. J Arid Environ 19(1):1-24

Mcffters SK (1996) The use of the normalized difference water index (NDWI) in the delineation of open water features. Int J Remote Sens 17(7):1425-1143

NASA-EOS (2006). NASA Earth observing system data gateway. Available from: http://delenn.gsfc.nasa.gov/ imswww/pub/ imswelcome/

Parinaz RB, Kenji O, Yo S (2012) Comparative evaluation of the vegetation dryness index (VDI), the temperature vegetation dryness index (TVDI) and the improved TVDI (iTVDI) for water stress detection in semi-arid regions of Iran. ISPRS J Photogramm Remote Sens 68:1-12

Price JC (1990) Using spatial context in satellite data to infer regional scale evapotranspiration. IEEE Trans Geosci Remote Sens 28(5): 940-948

Qi SH. (2004) Drought monitoring models with remote sensing and spatio-temporal characteristics of drought in China. The PHD thesis of Chinese Academy of Sciences.

Rahimzadeh BP, Omasa K, Shimizum Y (2012) Comparative evaluation of the vegetation dryness index (VDI), the temperature vegetation dryness index (TVDI) and the improved TVDI (iTVDI) for water stress detection in semi-arid regions of Iran. ISPRS J Photogramm Remote Sens 68:1-12

Rahimzadeh PB, Berg AA, Champagne C, et al. (2013) Estimation of soil moisture using optical/thermal infrared remote sensing in the Canadian Prairies. ISPRS J Photogramm Remote Sens 83(3):94 103

Rhee JY, Im J, Carbone GJ (2010) Monitoring agricultural drought for arid and humid regions using multi-sensor remote sensing data. Remote Sens Environ 114:2875-2887

Sachula LGX, Bao G, Bao YH, Wang ML (2012) The spatial and temporal changes of snow cover of the Mongolian plateau in recent 10 years. J Inn Mongolia Norm Univ (Nat Sci Ed) 9:0531-0536

Sandholt I, Rasmussen K, Andersen J (2002) A simple interpretation of the surface temperature/vegetation index space for assessment of surface moisture status. Remote Sens Environ 79(2-3):213-224

Seneviratne SI, Pal JS, Eltahir EAB, et al. (2002) Summer dryness in a warmer climate: a process study with a regional climate model. Clim Dyn 20:69-85

Shi C, Liu XD (2012) Continent drought characteristics over the eastern hemisphere from 1947 to 2006: analyses based on the SPEI dataset. J Desert Res 06:1691-1701

Shi YF, Shen YP, HR (2002) Preliminary study on signal impact and foreground of climate shift from warm-dry to warm-humid in Northwest China. J Glaciol Geocryol 24(3):219-223 
Shu YQ, Stisen S, Jensen, Karsten H, Sandholt (2011) Estimation of regional evapotranspiration over the North China Plain using geostationary satellite data. Int J Appl Earth Obs Geoinf 13(2):192-206

Stow D, Daeschner S, Hope A, et al. (2003) Variability of the seasonally integrated normalized difference vegetation index across the north slope of Alaska in the 1990s. Int J Remote Sens 24(5):1111-1117

Sun H, Zhao X, Chen Y, et al. (2013) A new agricultural drought monitoring index combining MODIS NDWI and day-night land surface temperatures: a case study in China. Int J Remote Sens 34(24): 8986-9001

Tian H, Wang CH, Wen J, et al. (2012) Soil moisture estimation over an arid environment in Mongolia from passive microwave remote sensing based on a simplified parameterization method. Chin J Geophys 55(2):415-427

Tucker CJ, Holben BN, Elgin JH, Mcmurtrey JE (1981) Remote-sensing of total dry-matter accumulation in winter-wheat. Remote Sens Environ 11(3):171-189

Vicente-Serrano SM, Cuadrat-Prats JM, Romo A (2006) Aridity influence on vegetation patterns in the middle Ebro Valley (Spain): evaluation by means of AVHRR images and climate interpolation techniques. J Arid Environ 66(2):353-375

Wang W, Feng ZD (2013) Holocene moisture evolution across the Mongolian plateau and its surrounding areas: a synthesis of climatic records. Earth Sci Rev 122:38-57

Wang C, Qi S, Niu Z, Wang J (2004) Evaluating soil moisture status in China using the temperature-vegetation dryness index (TVDI). Can J Remote Sens 30(5):671-679

Wang JS, Chen FH, Zhang Q, et al. (2008a) Temperature variations in arid and semi-arid areas in middle part of Asia during the last 100 years. Plateau Meteorol 5(27):1035-1045
Wang L, Zhen L, Liu XL, Ochirbat B, Wang QX (2008b) Comparative studies on climate changes and influencing factors in central Mongolian plateau region. Geogr Res 1:171-180

Wang H, Li XB, Long HL, et al. (2010) Monitoring the effects of land use and cover type changes on soil moisture using remote-sensing data: a case study in China's Yongding River basin. Catena 82(3):135145

Wang DW, Zhao J, Yin D, Han T, Li LL (2013) Potential vegetation dynamic analysis of spatial and temporal characteristics of Inner Mongolia's geographical pattern in recent 50 a. Pratacultural Sci 30(8):1167-1173

Xu H (2006) Modification of normalized difference water index (NDWI) to enhance open water features in remotely sensed imagery. Int J Remote Sens 27(14):3025-3033

Xue YK (1996) The impact of desertification in the Mongolian and Inner Mongolian grassland on the regional climate. J Clim 9(6):21732189

Yang XH, Zhuo G, Luo B (2011) On MODIS data based drought monitoring in Northwest China. Pratacultural Sci 28(08):1420-1426

Yu M, Cheng MH, Liu H (2011) An improvement of the land surface temperature-NDVI space drought monitoring method and its applications. Acta Meteorol Sin 69(5):922-931

Zhang XY, Zhang GY, Zhu GH, et al. (1996) Elemental tracers for Chinese source dust. Sci Chin Ser D 395:512-521

Zhang JY, Dong WJ, Fu CB (2005) The effects of the degradation in Northern China and Southern Mongolia on the regional climate. Chin Sci Bull 50(1):53-58

Zhao QY, Li DL, Wu HB (2006) Analysis on surface air temperature changes in east part of Northwest China in last 40 years. Plateau Meteorol 4(25):643-651 